\title{
The Effect of the Operational Parameters on Turbidity Removal Using Peanut Cake as Primary Coagulant
}

\author{
Ahmed H. Birima \\ Department of Civil Engineering, College of Engineering, Qassim University, Unaizah 51911, Saudi Arabia
}

Corresponding Author Email: ah.mohammed@qu.eu.sa

https://doi.org/10.18280/ijdne.160205

Received: 9 November 2020

Accepted: 6 April 2021

\section{Keywords:}

peanut cake, coagulation, turbidity, rapid mixing time, slow mixing time

\begin{abstract}
The drawbacks associated with traditional chemical coagulants used in water treatment, such as health-related and environmental adverse effects, have encouraged the search for natural alternatives, in particular plant-based coagulants. This study investigated the effect on turbidity removal of synthetic turbid water prepared by adding kaolin to distilled water of various operating parameters, namely the initial turbidity of the raw water, rapid mixing time and slow missing time. A plant-based, which was extracted from peanut cake, was used. Using Minitab tools, experiments were planned. Three levels were tested for each of the aforementioned parameters, namely 50, 100 and 150 NTU for initial turbidity; 1, 2 and 3 minutes for rapid mixing; and 15, 20 and 25 minutes for slow mixing. The results showed that the coagulant has a high ability to remove turbidity, with the removal percentage varying from $70 \%$ to $95 \%$. A one-way ANOVA showed a significant impact on the turbidity removal of each individual parameter. In addition, it revealed that there was a significant interaction between the initial turbidity and slow mixing time, and that of the rapid mixing time and slow mixing time. On the other hand, significant effect was also shown by the three-way interactions between the three parameters.
\end{abstract}

\section{INTRODUCTION}

Availability of potable water witnessed diminishing recently due to the current trends in development, which resulted in upsurge pollution as a result of growing economic activities, contributing to the annual death exceeded 2 million children under age 5 from water-borne and pneumonia related disease [1]. Rural communities of developing countries are more experiencing the lake of water due to insufficient water and wastewater treatment facilities [2, 3]. Moreover, speedy population growth and low level of personal hygiene are another factors contribute to this threat, which might cause water-borne disease [4]. Surface water encompasses billions of dissolved microscopic particles and impurities. These dissolved impurities contain minerals, organic and inorganic compounds that lead to changing of the physical, chemical and biological characteristics of water [5]. Therefore, treatment and purification of water from surface bodies is vital to meet the required limits for drinking water. Various purification techniques are applied, selection of each depends on the characteristics of water to be treated [6]. The purification process basically accomplished via coagulation and sedimentation processes, to allow dissolved impurities and colloidal particles to settled down by gravity; thus removing the turbidity. However, these colloidal particles are too small to settle individually therefore, they must agglomerate to increase their weight in order to be settle by gravity. The individual particles remain suspended due to their electrical negatively charges that make them repel each other. This is the reason led to the development of a process called coagulation, which used as preparation for sedimentation process [6].

Coagulation refers to the process whereby suspended mater in raw water is chemically destabilized so they agglomerate in larger particles known as flocs. Coagulants are the substances used for this purpose [7]. Coagulants are classified into inorganic or organic coagulants. Organic coagulants include the polyDADMAC (polydiallyldimethyl ammonium chloride) range of cationic polymers and Chitos; whereas, inorganic coagulants refer to the common chemicals that base on metals which basically aluminium or iron salts, such as ferric chloride, alum, calcium hydroxide ferrous sulphate, polyelectrolytes etc. [6]. The most widely used coagulant in developing countries is alum (aluminum sulphate) because of its high efficiency of turbidity removal. Nevertheless, some drawbacks associated with using alum have been discovered. These include, high cost, involvement in Alzheimer's disease, production of large volume of toxic nonbiodegradable sludge, ineffectiveness in low-temperature water, significant affect $\mathrm{pH}$ of treated water [8-12]. It is therefore there is need to replace these chemical coagulants with plant-based coagulants in order to offset the aforementioned drawbacks. The main advantages of using plant-based coagulants in water treatment include; cost effectiveness, they are not reducing the $\mathrm{pH}$ of the treated water, highly biodegradable. These advantages are more valuable if the plant from which the coagulant is extracted is native to a rural community [12].

In addition to the aforementioned advantages, the factor that motivated the present study, is the availability of peanut cake in most parts of the world; since it represents the fifth oilseed over the world after its ranking decreased from third as a result of the increasing importance of sunflower seed and rapeseed [13]. This make it affordable for the people in the remote parts of the world, particularly in developing countries, who are suffering a lack of clean drinking water. 
Polymeric coagulants are classified as cationic, anionic or nonionic, whereby the former two are collectively termed as polyelectrolytes [14]. Generally, natural coagulants are either polysaccharides or proteins. Many plant-based coagulants have been described, however, only four types are generally well-known within the scientific community, these are nirmali seeds (Strychnos potatorum), Moringa oleifera (horseradish or drumstick tree), tannin and cactus [12]

Peanut cake (PC) is a by-product of peanut oil production after the oil has been extracted. In some developing countries like Sudan it has been used as animals feeding and soil fertilizer. The reason of this, its high protein content which range between $41 \%$ to $45 \%$, it is also contains a fat ranging from $8 \%$ to $9 \%$ [15]. Recent studies have been conducted in investing the potential of peanut cake as a coagulant in water treatment. Nand et al. [16] used coagulant extracted from peanut seeds to remove heavy metals from a raw water in Fiji, it removed $50 \%$ and $40 \%$ of cadmium and chromium respectively. Other studies showed high potential of PC in removing turbidity from synthetic turbid water [17]. On the other hand, PC used to remove up to $94.7 \%$ of suspended solids and $73.5 \%$ of chemical oxygen demand (COD) from the palm oil mill effluent (POME) [18]. This study aims to investigate the effect of the operational parameters on the turbidity removal, using PC as primary coagulant. Twenty sets of experiments were designed, using fractional factorial design, to study the effect of the operational parameters, namely, initial turbidity, slow mixing time and rapid mixing time. Three levels of each parameter (low, medium and high) were investigated. The results were promising, as the PC was able to remove $70 \%$ to $95 \%$ of the turbidity from the synthetic water. The tested parameters were found to have significant effects on turbidity removal. This finding made the extension of this research to include the optimization of these parameters is vital.

\section{MATERIALS AND METHODS}

\subsection{Design of experiments}

Table 1. Experimental runs and their corresponding response (residual turbidity)

\begin{tabular}{cccc}
\hline $\begin{array}{c}\text { Test } \\
\text { run }\end{array}$ & $\begin{array}{c}\text { Initial } \\
\text { turbidity } \\
\text { (NTU) }\end{array}$ & $\begin{array}{c}\text { Slow mixing } \\
\text { time (minute) }\end{array}$ & $\begin{array}{c}\text { Rapid mixing } \\
\text { time (minute) }\end{array}$ \\
\hline Run 1 & 150 & 25 & 3 \\
Run 2 & 100 & 25 & 1 \\
Run 3 & 50 & 15 & 3 \\
Run 4 & 150 & 20 & 2 \\
Run 5 & 100 & 15 & 2 \\
Run 6 & 50 & 20 & 1 \\
Run 7 & 100 & 20 & 3 \\
Run 8 & 150 & 15 & 1 \\
Run 9 & 50 & 25 & 2 \\
Run & 50 & 20 & 2 \\
10 & & & \\
Run & 100 & 25 & 1 \\
11 & & & \\
Run & 150 & 15 & 1 \\
12 & & & \\
Run & 50 & 15 & \\
13 & & & \\
Run & 150 & 20 & \\
14 & & & \\
\hline
\end{tabular}

\begin{tabular}{cccc}
\hline $\begin{array}{c}\text { Run } \\
15\end{array}$ & 150 & 25 & 2 \\
$\begin{array}{c}\text { Run } \\
16\end{array}$ & 100 & 15 & 2 \\
$\begin{array}{c}\text { Run } \\
17\end{array}$ & 100 & 20 & 3 \\
$\begin{array}{c}\text { Run } \\
18\end{array}$ & 50 & 25 & 3 \\
$\begin{array}{c}\text { Run } \\
19\end{array}$ & 50 & 20 & 2 \\
$\begin{array}{c}\text { Run } \\
20\end{array}$ & 150 & 20 & 1 \\
\hline
\end{tabular}

The design of the experiments was carried out using the Minitab software. For this purpose, a fractional factorial design was chosen. Three parameters with three levels were studied-initial turbidity, rapid mixing time and slow mixing time, and their respective levels were 50, 100 and 150 NTU for initial turbidity; 1, 2 and 3 minutes for rapid mixing time; and 15,20 and 25 minutes for slow mixing time. The set of experiments is shown in Table 1. In fact, the actual values of the initial turbidity (column 2) are \pm 2 NTU, since it is practically difficult to get the exact value. In this table, the first column indicates the experiment number (run), while the second, third and fourth column indicate the initial turbidity, slow mixing time and rapid mixing time for each run respectively. For each run, the software alters the levels of these parameters based on low, medium or high level.

\subsection{Preparation of synthetic water}

The synthetic water used in this study was prepared using kaolin mixed with distilled water. Ten grams of kaolin have been added to one liter of distilled water. The water was blended for one hour at $80 \mathrm{rpm}$. After an hour, synthetic water was allowed to settle overnight. After the hydration culmination of the kaolin, the supernatant was gradually decanted and put in an alternate beaker. This was the stock solution used to prepare turbid water. It was diluted with tap water to obtain different turbidity ranges, i.e. 50, 100 and 150 NTU.

\subsection{Preparation of peanut stock solution}

The peanut cake used in this study was taken from a peanut oil factory known Al-Wagea oil factory, located in El-Obeid City (capital of northern Kurdufan state), northern Kurdufan state, Republic of Sudan. The factory produces the oil almost for the whole city, which its population in 2008 was 340,940; and distributes to other cities in the country. The process of peanut oil production consists of five steps - (1) Lamination, (2) Cooking (at $\left.110^{\circ} \mathrm{C}\right),(3)$ Pressing, (4) Solvent extraction, and (5) Solvent elimination process. In northern Kurdufan state generally, peanut cake is used as animal feed.

The solid cake was crushed into powder, then $250 \mathrm{mg} / 1$ of peanut powder was added to $250 \mathrm{ml}$ of sodium chloride $(\mathrm{NaCl})$ solution prepared by dissolving 3 moles of $\mathrm{NaCl}$ in one liter of distilled water. The mixture was blended for 10 minutes with a domestic blender to extract the peanut active ingredient. The completion was filtered by a standard filter paper (Watman GF / CTM) using a vacuum pump. This stock solution was later used for the preparation of different coagulant dosages.

\subsection{Jar test procedure}

In this study, the Jar tester (BIBBY Stuart Scientific, UK) 
was used for the coagulation test; for each experiment, the Jar tester was programmed for rapid mixing time and slow mixing time based on the test runs shown in Table 1; whereas the rapid mixing speed, slow mixing speed and settling time were maintained at $80 \mathrm{rpm}, 20 \mathrm{rpm}$ and 60 minutes respectively for all sets of experiments. Five hundred $\mathrm{ml}$ of turbid water (synthetic) was poured in six $1 \mathrm{~L}$ glass beakers. Coagulant dosages were added simultaneously to beakers using pipettes. The beakers then went into the jar test apparatus, where they underwent rapid mixing followed by slow mixing and then settling. After a settling time of $60 \mathrm{~min}$, the samples were removed from each beaker and tested for turbidity and $\mathrm{pH}$.

\section{RESULTS AND DISCUSSION}

\subsection{Potential of peanut cake in coagulation of turbid water}

Figure 1 shows the residual turbidity of the various experimental runs that have been conducted. Residual turbidity was obtained from the optimal run dosage. The lowest residual turbidity was observed at run 11 (6.3 NTU) with an initial turbidity of 102 NTU, a rapid mixing time of 1 minute and a slow mixing time of 25 minutes.

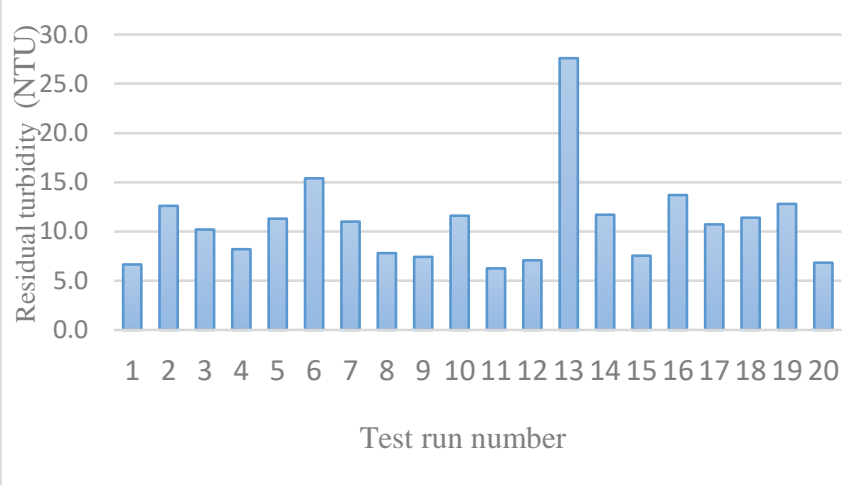

Figure 1. Residual turbidity at different combination of operational parameters

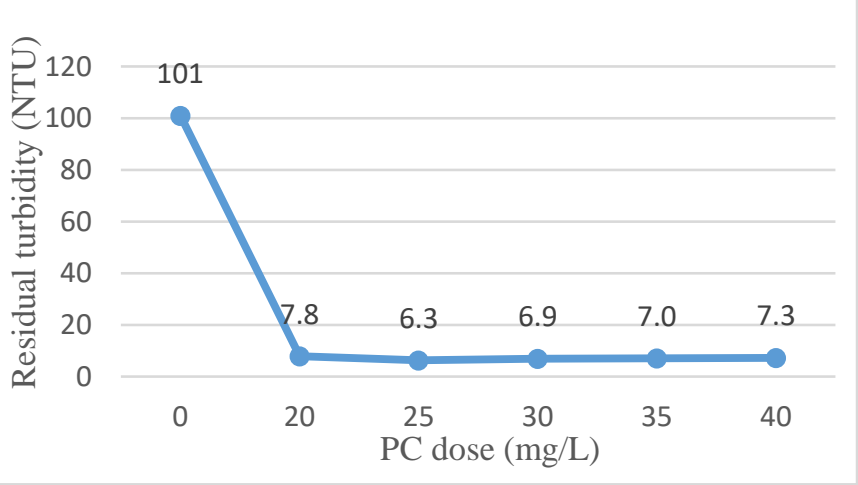

Figure 2. Residual turbidity versus coagulant dose for run 11

Figure 2 shows the variation of residual turbidity with the coagulant dose for run 11. It was observed that the turbidity decreased dramatically from 101 NTU by the addition of a coagulant dose to $6.3 \mathrm{NTU}$ at an optimum dose of $25 \mathrm{mg} / \mathrm{L}$, which achieved an elimination efficiency of 93.8 per cent. The optimum dose recognized by the lowest residual turbidity after which turbidity begins to increase as more coagulants are added. This result is comparable to that obtained by Birima et al. [17] in which the coagulant extracted from peanut seeds was able to achieve a removal efficiency of 92 per cent from synthetic water with an initial turbidity of 200 NTU. Moreover, the increase in turbidity beyond the optimum dose interpreted to re-stabilize destabilized, moreover, the coagulant itself (at high concertation) increases the turbidity $[6,19]$.

On the other hand, the initial $\mathrm{pH}$ and the final $\mathrm{pH}$ (at the optimum dose) remained constant at 6.48 , as shown in Table 2. Unlike alum, which normally reduces the $\mathrm{pH}$ of treated water drastically due to hydrolysis which releases $\mathrm{H}+$ ions [6], plant-based coagulants such as Moringa oleifera and Cactus Opunita have generally shown a slight decrease in $\mathrm{pH}$ with an increase in the coagulant dose [6]. This indicates that the PC coagulant has the same characteristics as the above mentioned coagulants for the effect of $\mathrm{pH}$ on water.

Table 2. Water quality parameters at initial and optimum conditions for run 11

\begin{tabular}{ccccc}
\hline Parameter & pH & $\begin{array}{c}\text { Color } \\
(\text { PtCo) }\end{array}$ & $\begin{array}{c}\text { Total } \\
\text { suspended } \\
\text { solid (mg/l) }\end{array}$ & $\begin{array}{c}\text { Turbidity } \\
\text { (NTU) }\end{array}$ \\
\hline Initial & 6.48 & 517 & 66 & 102.3 \\
Optimal & 6.48 & 8 & 12 & 6.3 \\
\hline
\end{tabular}

\subsection{Main and interaction effects of operating parameters} on the removal of turbidity

The analysis of variance for the parameters of interest was conducted using Minitab software. The initial turbidity, rapid mixing time and slow mixing time represented the factors, whilst, the residual turbidity was taken as the response. Figure 3 shows the input data in the software, whereas, the results of analysis are shown in Figure 4.

\begin{tabular}{|c|c|c|c|c|c|c|c|c|c|}
\hline \multicolumn{10}{|c|}{ 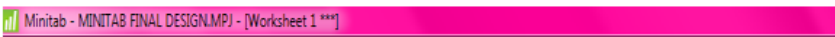 } \\
\hline \multicolumn{10}{|c|}{ 圈 Elle Egdit Dạto Calc Stat Graph Edgitor Iools Window Help Assistant } \\
\hline \multicolumn{10}{|c|}{ 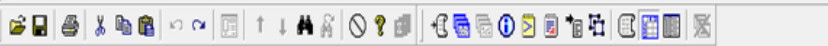 } \\
\hline \multicolumn{10}{|c|}{ 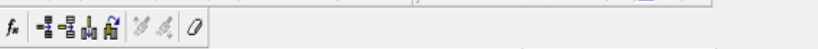 } \\
\hline \multicolumn{4}{|c|}{ 可国 $|+\beta+\beta \neq|$} & $\nabla \times 10$ & \multicolumn{3}{|c|}{ a $\mid \wedge \mathrm{T} \square 0 \backslash \circ \square \square$} & \multirow[b]{2}{*}{ C8 } & \multirow[b]{2}{*}{ C9 } \\
\hline+ & & $\mathrm{C2}$ & C3 & $\mathrm{C} 4$ & C5 & C6 & C7 & & \\
\hline & Initial Turbidity & Slow Mixing & Rapid Mixing & Optimal Residual turbidity & StdOrder & RunOrder & Blocks & CenterPt & \\
\hline 1 & 151.0 & 25 & 3 & 6.65 & 1 & 1 & 1 & 1 & \\
\hline 2 & 101.0 & 25 & 1 & 12.60 & $\sqrt{2}$ & 2 & 1 & 1 & \\
\hline 3 & 522 & 15 & 3 & 10.20 & 3 & 3 & 1 & 1 & \\
\hline 4 & 151.0 & 20 & 2 & 8.20 & 4 & 4 & 1 & 1 & \\
\hline 5 & 102.5 & 15 & 2 & 11.30 & 5 & 5 & 1 & 1 & \\
\hline 6 & 49.8 & 20 & 1 & 15.40 & 6 & 6 & 1 & 1 & \\
\hline 7 & 101.0 & 20 & 3 & 11.00 & 7 & 7 & 1 & 1 & \\
\hline 8 & 152.0 & 15 & 1 & 7.80 & 8 & 8 & 1 & 1 & \\
\hline 9 & 52.3 & 25 & 2 & 7.42 & 9 & 9 & 1 & 1 & \\
\hline 10 & 51.5 & 20 & 2 & 11.60 & 10 & 10 & 1 & 1 & \\
\hline 11 & 102.3 & 25 & 1 & 6.25 & 11 & 11 & 1 & 1 & \\
\hline 12 & 149.0 & 15 & 3 & 7.07 & 12 & 12 & 1 & 1 & \\
\hline 13 & 52.0 & 15 & 1 & 27.60 & 13 & 13 & 1 & 1 & \\
\hline 14 & 152.0 & 15 & 1 & 11.70 & 14 & 14 & 1 & 1 & \\
\hline 15 & 149.0 & 25 & 2 & 7.54 & 15 & 15 & 1 & 1 & \\
\hline 16 & 101.7 & 15 & 2 & 13.70 & 16 & 16 & 1 & 1 & \\
\hline 17 & 99.9 & 20 & 3 & 10.72 & 17 & 17 & 1 & 1 & \\
\hline 18 & 51.8 & 25 & 3 & 11.40 & 18 & 18 & 1 & 1 & \\
\hline 19 & 53.4 & 20 & 2 & 12.80 & 19 & 19 & 1 & 1 & \\
\hline 20 & 150.5 & 20 & 1 & 6.83 & 20 & 20 & 1 & 1 & \\
\hline
\end{tabular}

Figure 3. Input data for experimental results

In this analysis, the confidence level (CL) was set at 95 per cent, which means that $\alpha$ was equal to 0.05 , therefore any effect with a P-value less than 0.05 is statistically significant, whereas that with a $\mathrm{P}$-value greater than 0.05 is insignificant. 
The main and interaction effects are discussed in the following paragraphs on the basis of the results of Figure 3.

\subsection{Main effects}

As Figure 4 shows, the P-value for initial turbidity, slow mixing time and rapid mixing time which was $0.002,0.002$ and 0.012 respectively, and the corresponding $T$ values were 3.96 , -0.384 and -0.295 . This indicates that the individual effects of each parameter on turbidity removal was significant.

\subsection{Two ways and three ways interactions}

The results of the analysis (Figure 4) also showed that there was a significant interaction between the initial turbidity and the slow mixing time; and between the slow mixing time and the rapid mixing time with the respective $p$-values of 0.017 and 0.006. However, the interaction between the initial turbidity and the rapid mixing time does not have a significant effect $(\mathrm{p}$ $=0.333$ ). The combination of the three parameters showed a significant effect on the removal of turbidity with a P-value equal to 0.022 .

With regard to the indication of the coefficients, the positive sign indicates that the factor and the response are directly proportional, while the negative sign indicates that they are inversely proportional. Consequently, the initial turbidity, which showed a coefficient of-2,635, was inversely proportional to the residual turbidity; which means that the higher the initial turbidity, the lower the residual turbidity (i.e. the higher the turbidity removal). In other words, the removal of turbidity increased with an increase in the initial turbidity of the raw water. Asrafuzzaman et al. [19] studied the potential of three different plant-based coagulants, namely Moringa oleifer, Cicer arietinum and Dolichos lablab, to remove turbidity of water at different turbidity levels, and the researchers reported that the three coagulants were best performed for higher initial turbidity. Therefore, the present finding implies that the PC behaves like the coagulants mentioned above. This could also indicate that the four coagulants have the same turbidity removal mechanism [20]. Similar relations are shown in Figure 4 for slow mixing time and rapid mixing time with respective coefficients of -2.43 and -1.868 ; which shows that both variables were inversely propositional with residual turbidity.

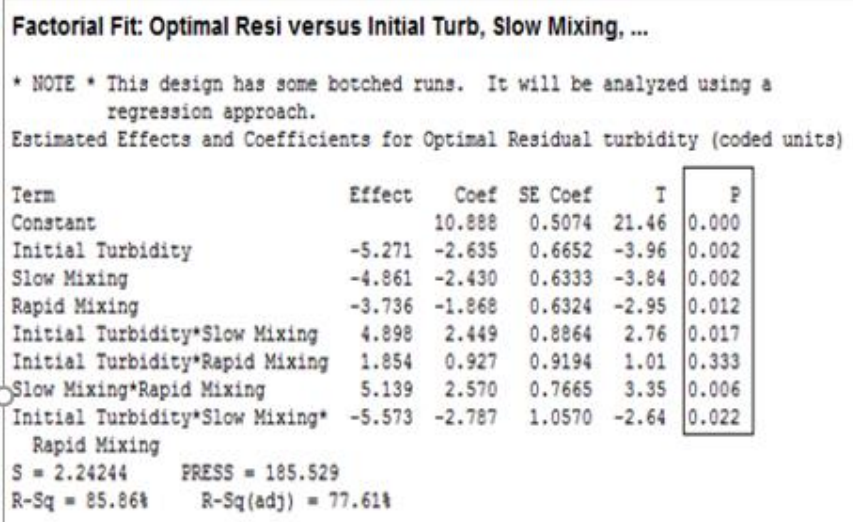

Figure 4. Analysis of variance for the experimental data

Introducing of peanut cake as coagulant for turbidity removal is useful addition to this field, particularly for the remote communities in the developing countries that face a lack of clean drinking water; and where the peanut is available. Such study with some additional experiments, will definitely add benefit to those communities; as it leads to optimization of using PC coagulant.

\section{CONCLUSION}

The effect of the operating parameters - initial turbidity of raw water, rapid mixing time and slow mixing time on coagulation of turbid water using coagulant extracted from peanut cake was tested in this paper. The total removal of turbidity for the different range of initial turbidity was found to be between $70 \%$ and $95 \%$. One-way ANOVA showed that the removal of turbidity ( $\mathrm{p}$-value $<0.05$ ) was significantly affected by each individual parameter. Whereas, in two ways interacting parameters, the analysis showed that the combination of initial turbidity with slow mixing time and the combination of slow mixing time and rapid mixing time had a significant effect. However, the interaction between the initial turbidity and the rapid mixing time did not have a significant effect $(\mathrm{p}=0.333)$. In addition, the three-way interactions between the three parameters also showed significant effects.

Previous studies- Birima et al. [17, 18] have proved the potential of peanut cake in removing turbidity of synthetic water, and the TSS and COD of POME, however, the effect of the operational parameters was not investigated. Therefore, the current study adds considerable contribution to those studies.

This study limits to three levels of each parameter as indicated in section 2.1. However, the next direction will focus on the extension of the study to include wider range of levels, and the optimization of these parameters, in order to come out with the overall optimum condition for the application of PC in coagulation process.

\section{REFERENCES}

[1] Taiwo, A.S., Adenike, K., Aderonke, O. (2020). Efficacy of a natural coagulant protein from Moringa oleifera (Lam) seeds in treatment of Opa reservoir water, Ile-Ife, Nigeria. Heliyon, 6(1): e03335. https://doi.org/10.1016/j.heliyon.2020.e03335

[2] Kuta, G.I., Emigilati, M.A., Hassan, A.B., Ibrahim, I. (2014). Domestic water sources and its health implication in Lapai Local Government area, Niger State, Nigeria. Ethiopian Journal of Environmental Studies and Management, 7(6): 686-694. http://dx.doi.org/10.4314/ejesm.v7i6.12

[3] Akinyoola, K.A., OdekanyiN, O.O., Adenike, K.U.K.U., SOSAN, M.B. (2016). Anti-insect potential of a lectin from the tuber, Dioscorea mangenotiana towards Eldana saccharina (Lepidoptera: Pyralidae). Journal of Agricultural Biotechnology and Sustainable Development, $\quad 8(3)$ : 16-26. http://dx.doi.org/10.5897/JABSD2015.0249

[4] Isikwue, M.O., Chikezie, A. (2014). Quality assessment of various sachet water brands marketed in Bauchi metropolis of Nigeria. International Journal of Advances in Engineering and Technology, 6(6): 2489-95.

[5] Devrimci, H.A., Yuksel, A.M., Sanin, F.D. (2012). Algal alginate: A potential coagulant for drinking water treatment. Desalination, 299: 16-21. https://doi.org/10.1016/j.desal.2012.05.004 
[6] Gandiwa, B.I., Moyo, L.B., Ncube, S., Mamvura, T.A., Mguni, L.L., Hlabangana, N. (2020). Optimisation of using a blend of plant based natural and synthetic coagulants for water treatment: (Moringa OleiferaCactus Opuntia-alum blend). South African Journal of Chemical Engineering, 34: 158-164. https://doi.org/10.1016/j.sajce.2020.07.005

[7] Gebbie, P. (2006). An operators guide for water treatment coagulants. Proceedings of the 31st Annual Qld Water Industry Workshop-Operations Skills, University Central Queensland; Rockhampton, Australia, 14-20.

[8] Rajendran, R., Abirami, M., Prabhavathi, P., Premasudha, P., Kanimozhi, B., Manikandan, A. (2015). Biological treatment of drinking water by chitosan based nanocomposites. African Journal of Biotechnology, 14(11): 930-936. https://doi.org/10.5897/ajb2015.14469

[9] Ribes, D., Colomina, M.T., Vicens, P., Domingo, J.L. (2010). Impaired spatial learning and unaltered neurogenesis in a transgenic model of Alzheimer's disease after oral aluminum exposure. Current Alzheimer Research, 7(5): 401-408. https://doi.org/10.2174/156720510791383840

[10] Walton, J.R. (2013). Aluminum involvement in the progression of Alzheimer's disease. Journal of Alzheimer's $\quad$ Disease, 35(1): 7-43. https://doi.org/10.3233/JAD-121909

[11] Camacho, F.P., Sousa, V.S., Bergamasco, R., Teixeira, M.R. (2017). The use of Moringa oleifera as a natural coagulant in surface water treatment. Chemical Engineering Journal, 313: 226-237. https://doi.org/10.1016/j.cej.2016.12.031

[12] Yin, C.Y. (2010). Emerging usage of plant-based coagulants for water and wastewater treatment. Process Biochemistry, 45(9): 1437-1444 https://doi.org/10.1016/j.procbio.2010.05.030

[13] Fletcher, S.M., Shi, Z. (2016). An overview of world peanut markets. Peanuts, 267-287. https://doi.org/10.1016/B978-1-63067-038-2.00010-1

[14] Bolto, B., Gregory, J. (2007). Organic polyelectrolytes in water treatment. Water Research, 41(11): 2301-2324. https://doi.org/10.1016/j.watres.2007.03.012

[15] Bezerra, L.S., Barbosa, A.M., Carvalho, G.G.P., Simionato, J.I., Freitas Jr, J.E., Araújo, M.L.G.M.L., Carvalho, B.M.A. (2016). Meat quality of lambs fed diets with peanut cake. Meat Science, 121: 88-95. https://doi.org/10.1016/j.meatsci.2016.05.019

[16] Nand, V., Maata, M., Koshy, K., Sotheeswaran, S. (2012). Water purification using Moringa oleifera and other locally available seeds in Fiji for heavy metal removal. International Journal of Applied Science and Technology, 2(5): 125-129.

[17] Birima, A.H., Hammad, H.A., Desa, M.N.M., Muda, Z. C. (2013). Extraction of natural coagulant from peanut seeds for treatment of turbid water. In IOP Conference Series: Earth and Environmental Science. IOP Publishing Ltd, 1: 1-4. https://doi.org/10.1088/17551315/16/1/012065

[18] Birima, A.H., Ahmed, A.T., Noor, M.J.M.M., Sidek, L.M., Muda, Z.C., Wong, L.S. (2015). Application of salt extracted peanut seeds in the pretreatment of palm oil mill effluent (POME). Desalination and Water Treatment, 55(8): https://doi.org/10.1080/19443994.2014.930696

[19] Gunaratna, K.R., Garcia, B., Andersson, S., Dalhammar, G. (2007). Screening and evaluation of natural coagulants for water treatment. Water Science and Technology: Water Supply, 7(5-6): 19-25. https://doi.org/10.2166/ws.2007.147

[20] Asrafuzzaman, M., Fakhruddin, A.N.M., Hossain, M. (2011). Reduction of turbidity of water using locally available natural coagulants. ISRN Microbiology. https://doi.org/10.5402/2011/632189 